\title{
Blocking Type I Interferon Production: A New Therapeutic Option to Reduce the HIV-1-Induced Immune Activation
}

\author{
Moritz Ries, Kathrin Pritschet, and Barbara Schmidt \\ Institute of Clinical and Molecular Virology, German National Reference Centre for Retroviruses, Friedrich-Alexander-Universität \\ Erlangen-Nürnberg, Schlossgarten 4, 91054 Erlangen, Germany
}

Correspondence should be addressed to Barbara Schmidt, baschmid@viro.med.uni-erlangen.de

Received 1 September 2011; Accepted 7 October 2011

Academic Editor: Mirko Paiardini

Copyright ( 2012 Moritz Ries et al. This is an open access article distributed under the Creative Commons Attribution License, which permits unrestricted use, distribution, and reproduction in any medium, provided the original work is properly cited.

Highly active antiretroviral therapy has dramatically improved the morbidity and mortality of HIV-1-infected individuals. A total of 25 licensed drugs provide the basis for an optimized virus-suppressive treatment of nearly each subject. The promises of immune reconstitution and normal life expectancy, however, fall short for a number of patients, either through inadequate recovery of CD4+ T-cell counts or the occurrence of non-AIDS defining malignancies. In this respect, the prevalence of Epstein-Barr virusassociated Hodgkin lymphoma and human papillomavirus-related anal neoplasia is rising in aging HIV-1-infected individuals despite antiretroviral therapy. An important cause appears to be the HIV-1-induced chronic immune activation, propagated by inappropriate release of proinflammatory cytokines and type I interferons. This immune dysregulation can be reduced in vitro by inhibitors blocking the endosomal acidification. Recent data suggest that this concept is also of relevance in vivo, which opens the door for adjuvant immunomodulatory therapies in HIV-1 infection.

\section{Old Problems Solved: New Arise}

In the past 15 years, the antiretroviral therapy has considerably advanced. Due to efforts of basic and clinical sciences and pharmaceutical companies, a total of 25 antiretroviral drugs are available which target different steps of the HIV-1 replication cycle, namely, entry, reverse transcription, integration, and processing of the gag-pol precursor [1]. This variety of drugs allows to select the optimal antiretroviral combination for nearly each HIV-1-infected individual [2], promising an efficient and long-term virus suppression with reconstitution of the immune system and almost normal life expectancy. With growing experience in antiretroviral treatment, however, evidence also increases that not all HIV-1-infected patients profit or continue to profit from the blessings of antiretroviral therapy. Obviously, suppression of viral load below detection limit does not completely reduce inflammation. As a result, long-term antiretrovirally treated patients still have an increased risk of death due to non-AIDS complications, which are typically associated with aging, for example, cardiovascular disease, osteoporosis, and end-organ failure [3]. Most notably, the prevalence of non-AIDS-associa- ted malignancies is increasing, for example, Epstein-Barr virus-associated Hodgkin lymphoma and human papillomavirus-associated anal neoplasia [4].

Do HIV-1-infected subjects now just live long enough to experience their tumor? Or are these complications a result of the persistent immune activation? If this is the case, we need to think about adjunctive therapeutical approaches to limit the level of immune activation. One of the most proinflammatory messengers in the body is the type I interferons. Therefore, this review aims to link current models of IFN-alpha induction and suppression in human and simian models of lentiviral infections with the results of most recent clinical studies. The readers are also referred to three excellent reviews which summarize the findings about the HIV-1induced immunopathogenesis [5-7].

\section{Beyond HIV}

"Complete" inhibition of viral replication-measured by the reduction of the viral load below detection limit-is obviously not sufficient to reverse the HIV-1-induced 
immunological damage in all patients. One reason may be that the peripheral viral load does not reliably reflect the situation in the lymphatic tissue [8]. Another explanation is that the HIV-1-associated chronic immune activation, which has recently come into the focus of scientific interest, plays a more important role than previously thought. Early studies in HIV-1-infected patients showed that the progression to AIDS was more strongly associated with levels of chronic immune activation than with viral loads [9-13]. Not only in humans, but also in the macaque model, it was shown that immune activation played a crucial role in lentiviral pathogenesis. The infection with simian immunodeficiency viruses (SIV) is usually apathogenic in the natural hosts like sooty mangabeys or African green monkeys [14, 15], whereas the infection of rhesus macaques with pathogenic SIV strains resembles the progressive course of human HIV-1 infection [16]. Pathogenic and apathogenic lentiviral infections are characterized by comparable viral loads in acute and chronic phases of the disease and a similar degree of CD4+ T cell destruction in cell culture [7]. In contrast, T-cell activation and programmed cell death as well as the secretion of proinflammatory cytokines are significantly enhanced in pathogenic infections, which progress with a decline in helper $\mathrm{T}$ cells and the occurrence of opportunistic infections [7].

\section{Trigger of Immune Stimulation}

An important stimulus for the chronic immune activation is the massive destruction of CD4+ T cells in the gastrointestinal tract, which has been observed in primary and chronic HIV-1 and SIV infections [17-22]. The resulting breach of the mucosal barrier supports the translocation of intestinal bacteria, which induces the production of proinflammatory cytokines, type I interferons and a systemic immune activation through the lipopolysaccharide (LPS) of gram-negative species, and other microbial constituents [23]. As an indicator of microbial translocation, circulating LPS levels are elevated in HIV-1-infected individuals [17, 23] and SIVinfected rhesus macaques [24]. Increased LPS levels in the plasma were correlated with chronic immune activation and were only partially reduced after administration of antiretroviral therapy [23].

Another potent trigger of immune stimulation is the type I interferons. In 1957, Alick Isaacs und Jean Lindenmann discovered a soluble substance, termed "interferon", which interfered with the influenza virus infection in cell culture [25]. Meanwhile, a whole family of interferons and interferon-like molecules have been identified [26]. Amongst them are the strongly antiviral, antiproliferative, and immunomodulatory type I interferons, mostly comprising IFNalpha and IFN-beta. In 1999, the plasmacytoid dendritic cells (PDC) were identified as major producers of these interferons in the blood $[27,28]$. Although accounting for only $0.2-$ $0.5 \%$ of peripheral blood mononuclear cells, PDC produce up to 1000-fold more IFN-alpha than any other cell in the body [29]. Armed with the endosomal Toll-like receptors (TLR) 7 and 9, PDC detect single-stranded RNA and CpGlike DNA molecules, respectively [30]. These cells drive a potent Th1 polarisation upon stimulation with respective bacterial and viral ligands, thus acting as "watchdogs" of the immune system $[31,32]$. It should be considered that other cell types besides PDC also produce type I IFN, which may be important in particular on a tissue or host basis.

\section{The Endosomal Enigma}

High-titered infectious and noninfectious HIV-1 [33-38] and in particular HIV-1-infected cells $[39,40]$ induce a robust IFN-alpha production. The attachment of virions to PDC is crucially dependent on binding of the viral envelope protein gp120 to the CD4 receptor on PDC, supported by the finding that the degree of IFN-alpha induction is correlated with the affinity of the virus to CD4 [41]. In addition, the PDC-specific C-type lectin BDCA2 [42] and the mannose receptor [43] were reported to be involved in the attachment of HIV-1 to PDC. After binding, HIV-1 can interact with the coreceptors and infect the PDC [44], which has been observed for CCR5- and CXCR4-tropic viruses [38, 40, 45-47]. Productive infection can be enhanced by maturation of PDC via CD40 ligand, which reduces their capacity to produce type I interferons, or by neutralizing secreted interferons using respective antibodies $[34,44]$.

The induction of type I interferon production by HIV-1, however, is independent of coreceptor usage and fusion with the plasma membrane $[33,37,40,41]$. Notably, the IFNalpha induction could be blocked by drugs which interfere with the endosomal acidification, for example, chloroquine, bafilomycin, ammonium chloride, and chlorpromazine [33, $39,40,48]$. Together with the colocalization of HIV-1 with the early endosomal antigen 1 in PDC [49], these findings suggest that virions are taken up into endosomal compartments of PDC. A key observation was that virions which were no longer able to package viral RNA were severely impaired in the IFN-alpha induction, indicating that viral nucleic acids are required for the activation of PDC [33]. This finding is consistent with the IFN-alpha induction by guanosin- and uridine-rich single-stranded RNA motifs derived from the $5^{\prime}$ untranslated region of HIV-1, which have been reported to interact with TLR7 and TLR8 [50]. Whether TLR9 also plays a role in this process is still controversially discussed. In this respect, we observed that the IFN-alpha induction by HIV-1-infected cells was blocked by lower concentrations of chloroquine than a synthetic TLR7 ligand [40]. When TLR-specific inhibitory oligonucleotides were used in the macaque model, a role for TLR9 in the induction of IFNalpha production by SIV could not be excluded [51]. In a most recent study, however, TLR7 was silenced by siRNA in a plasmacytoid cell line; thereby, the authors could show that the majority of IFN-alpha production by HIV-1-infected cells is through TLR7 [39]. Moreover, when 293T cells, which do not express endosomal TLRs, were transfected with CD4 and CXCR4 and subsequently exposed to HIV-1-infected cells, an IFN-beta promoter was induced [39]. These findings provide first evidence that HIV-1 RNA may be recognized by cytosolic pattern recognition receptors, which induces a type I interferon production through interferon response factor (IRF) 3 . 
Altogether, the data support a model (Figure 1), in which the IFN-alpha production is initiated by the endocytic uptake of virions into PDC. Nucleic acids are released upon endosomal acidification and preferentially interact with TLR7 to promote a signaling cascade via MyD88 and IRF7. The relevance of the TLR-independent recognition of HIV-1 in PDC still has to be analyzed.

\section{The Vicious Circle of Type 1 Interferons}

The induction of type I interferons has beneficial effects, as HIV-1-infected cells are driven into the programmed cell death [6], and viral replication is reduced by $1(-2) \log$ $[44,52,53]$. However, the increased induction of IFN-alpha production by infectious and noninfectious virions is also detrimental, as addressed by several groups (reviewed in [54]). In this respect, it was shown by the group of Gene Shearer, NIH Bethesda, that the TNF-related apoptosis-inducing ligand (TRAIL) and its death receptor (DR) 5 was induced on CD4+ T lymphocytes in the peripheral blood and in secondary lymphatic tissue $[36,37,55]$. This mechanism leads to the apoptosis of uninfected $\mathrm{CD} 4+\mathrm{T}$ cells, thereby contributing to the characteristic destruction of the lymph node architecture in advanced stages of HIV-1 infection. Moreover, the PDC-derived IFN-alpha induces the immunosuppressive enzyme indoleamine-2,3-dioxygenase (IDO), which leads to reduced CD4+ T-cell proliferation and T-cell dysfunction $[56,57]$ and enhanced activity of T-regulatory cells [58]. Concomitantly with these findings, a signature of increased IFN-alpha production, namely, the upregulation of IFN-responsive genes, is observed in peripheral cells and in the lymphatic tissue of HIV-1-infected individuals $[36,37,55,59,60]$. These data have been confirmed in primate lentiviral models, in which pathogenic SIV infections were associated with increased IFN-alpha and TRAIL levels [51, 61]. Further corroboration comes from studies of apathogenic SIV infections, in which the strong type I interferon response in acute infections was quickly downregulated, whereas persistent IFN-alpha production was observed during pathogenic SIV infection of rhesus macaques [6265].

Is the immune stimulation reflected by an elevated level of circulating type I interferons in HIV-1-infected individuals? Older studies say so [66-68], but this has recently been questioned when similar IFN-alpha levels were measured in viremic and aviremic HIV-1-infected individuals and uninfected controls [69]. An explanation may be that elevated IFN-alpha levels in the periphery are primarily present in patients with end-stage disease. In countries with access to highly active antiretroviral therapy, however, these individuals have become rare. Another important aspect is that HIV1 -infected cells induce 10-100-fold more IFN-alpha compared to cell-free virions, as shown by the use of transwell chambers and gentle shaking of cocultures $[39,40]$. These findings are consistent with an increased transfer of viruses by filopodial bridges [70]. Thus, the major release of IFNalpha - and consequently its detrimental effects-appear to occur preferentially in the lymphatic tissue, where HIV-1infected cells are in close contact with PDC, which enhances cell-to-cell transfer of HIV-1 [71]. In a recent in vivo study, PDC accumulated in the spleens of HIV-1-infected subjects [72]. Interestingly, IFN-alpha did not colocalize with PDC but other cells, for example, $\mathrm{T}$ and $\mathrm{B}$ cells, which may reflect uptake of the cytokine via IFN-alpha receptors [72]. Another important site is the mucosal tissue, to which PDC are recruited in pathogenic SIV infection of rhesus macaques [73].

The increased type I interferon production upon stimulation with HIV-1-infected cells in the lymphatic tissue is faced by a decreased IFN-alpha response of peripheral cells to TLR stimulation. On the one hand, this is due to reduced PDC counts in HIV-1 infection, which has been confirmed by many groups (reviewed in [5]). On the other hand, progressive disease comes along with functional PDC deficits, in particular, reduced IFN-alpha production upon stimulation with TLR7 and TLR9 agonists [74-78]. In early stages of HIV-1 infection (Fiebig V-VI), however, PDC retain the ability to respond to TLR7/8 stimulation [79]. Notably, numerical and functional PDC deficits are not completely restored by antiretroviral therapy $[80,81]$. The ongoing innate immune defect may account for the increase of viral infections and associated tumors that are in principle susceptible to type I interferons. In this respect, it is intriguing to look at the spectrum of opportunistic infections in the immune reconstitution inflammatory syndrome, which occurs in about $20 \%$ of HIV-1-infected individuals on newly initiated antiretroviral therapy. Besides genital warts, there is a high frequency of genital herpes, molluscum contagiosum, and varicella-zoster virus [82], which are known or suspected to be TLR9 agonists [83]. Similarly striking is the increase of papillomavirus-associated anal neoplasia in HIV-1-infected patients despite antiretroviral therapy; these lesions are responsive to the TLR7 agonist imiquimod [4, 84].

How can the reduced responsiveness of PDC to TLR stimulation in the periphery be put together with the enhanced IFN-alpha release particularly in the lymphatic tissue? Tilton and colleagues provided an appealing explanation saying that PDC were preactivated via type I IFNs or virions in vivo, which prohibited de novo stimulation in vitro [60]. This has been questioned by a recent study, which showed prolonged and repeated IFN-alpha signaling in PDC exposed to HIV-1 due to an inability of endosomes to mature [49]. Another hypothesis may be that the HIV-1-induced immune stimulation somehow actively suppresses the induction of IFN-alpha production. As a result, PDC are no longer able to fulfill their purpose as "watchdogs" of the immune system: they now resemble "a dog that bites its tail." A model for the ambiguous role of type I interferons in the immunopathogenesis of HIV-1 infection is proposed in Figure 2.

\section{From Bench to Bedside}

If one adopts the concept of chronic immune activation as a major factor in the HIV-1 progression, the therapeutic consequence would be to limit this immune stimulation. A proof of principle was provided by early studies using low-dose prednisolone, which significantly stabilized CD4+ T-cell 


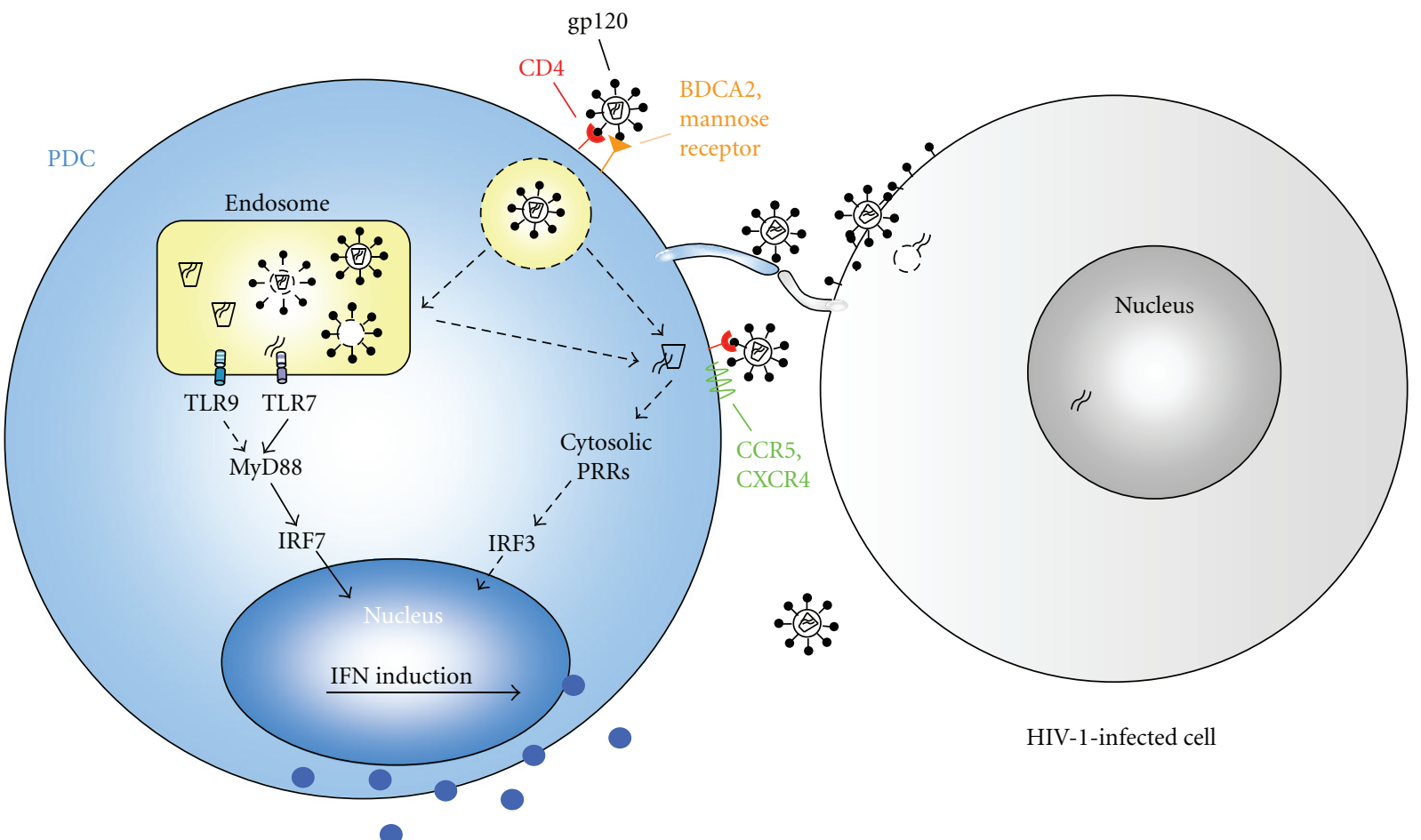

Figure 1: Proposed model of the type I interferon induction by HIV-1 and HIV-1-infected cells. Attachment to the CD4 receptor of plasmacytoid dendritic cells (PDC) triggers the HIV-1 uptake into an endosomal compartment. Subsequent acidification releases nucleic acids from lysed virions, preferentially recruits Toll-like receptor (TLR) 7, and activates the MyD88-dependent pathway. Translocation of the interferon response factor (IRF) 7 into the nucleus activates production of type I interferons (IFN). HIV-1 can also infect PDC via interaction with CD4 and the coreceptors. So far, it is unclear whether virions can escape from the endosomal compartment and initiate productive infection. Another pathway of type I interferon production was recently described in the absence of endosomal TLRs, namely, the recognition of HIV-1 RNA via cytosolic pattern recognition receptors (PRR) and IRF3 [39]. The role of this pathway for the IFN-alpha induction in PDC needs to be further elucidated.

TABLE 1: Effect of chloroquine on the HIV-1 and SIV-induced type I interferon production and/or subsequent immune activation in vitro and in vivo.

\begin{tabular}{llll}
\hline Study & Design & Species & Read-out \\
\hline$[33,40]$ & In vitro & Human & Reduced IFN-alpha production \\
\hline$[51]$ & In vitro & Rhesus & Reduced IFN-alpha production \\
\hline$[89]$ & In vitro & Human & $\begin{array}{l}\text { Reduced IFN-alpha production, reduced CD8+ T-cell } \\
\text { activation (CD38), block of negative modulators of the } \\
\text { T-cell response (IDO, PDL-1), reduced PDC activation } \\
\text { and maturation }\end{array}$ \\
\hline$[91]$ & In vivo & Human & $\begin{array}{l}\text { Reduced CD8+ cell activation (CD38+ HLA-DR+), } \\
\text { reduced CD4+ and CD8+ T-cell proliferation (Ki-67) }\end{array}$ \\
\hline & & $\begin{array}{l}\text { Reduced CD4+ T-cell proliferation (Ki-67), reduced } \\
\text { activation of CD8+ T cells (CD38+ HLA-DR+) and } \\
\text { monocytes (CD69), reduced plasma LPS levels, reduced } \\
\text { proinflammatory cytokines (IL-6, TNF-alpha), increase } \\
\text { in CD4+ T-cell percentages }\end{array}$ \\
\hline
\end{tabular}

counts in otherwise untreated HIV-1-infected patients [85]. These data were corroborated in individuals on HAART, although the effect on the CD4+ T cells was smaller [86]. In early studies by the group of Zagury, a total of 27 and 242 HIV-1-infected subjects were vaccinated against IFN-alpha$2 \mathrm{~b}$ in a phase I/II study and a double-blind placebo-controlled phase II/III clinical trial, respectively [87, 88].
Although the immunogenicity of the vaccine was low, individuals who responded to vaccination had a lower rate of disease progression.

A different approach was used in recent studies, which focused on the effect of chloroquine on the HIV-1-related immune activation (summarized in Table 1). Chloroquine, which interferes with the endosomal acidification, is licens- 


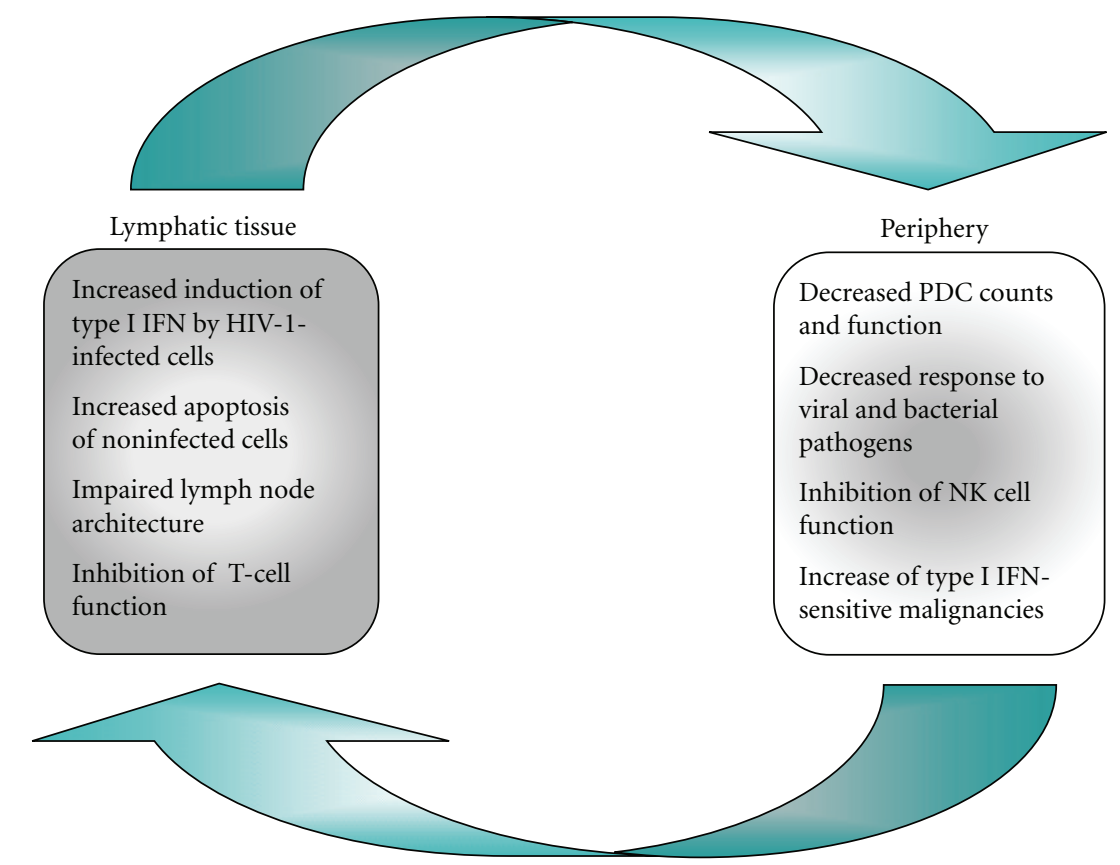

FIGURE 2: Vicious circle of type I interferon (IFN) induction in HIV-1 infection. The IFN-alpha induction is no longer balanced in HIV-1 infection. In the lymphatic tissue, plasmacytoid dendritic cells (PDC) are activated through direct cell-to-cell contact with HIV-1-infected cells, which creates an interferon-rich environment, promotes the apoptosis of uninfected $\mathrm{T}$ cells, inhibits $\mathrm{T}$-cell functions, and destroys the lymph node architecture. In the periphery, reduced PDC counts and function result in an impaired innate immune response to bacterial and viral stimuli. Decreased natural killer (NK) cell functions may enhance the susceptibility to opportunistic infections and virus-induced tumor growth. The occurrence of pathogens in the periphery further causes PDC activation and depletion into lymphatic tissues.

ed for the prophylactic treatment of malaria. It is also widely used in the treatment of autoimmune disorders, for example, the rheumatoid arthritis, to curb the chronic immune activation. In cell culture, chloroquine inhibited the induction of IFN-alpha production by HIV-1 and HIV-1-infected cells, as outlined above. Chloroquine also decreased CD8+ T-cell activation and blocked two negative regulators of the T-cell response, IDO, and programmed death ligand 1 [89]. When mice were treated with chloroquine, the production of proinflammatory cytokines upon stimulation with LPS was reduced [90]. These data were recently supported and extended by two clinical trials with HIV-1-infected individuals. In the first study, chloroquine was administered to 13 HAART-naïve subjects for 2 months [91]. The patients showed immunological improvement, as the frequency of CD38+ HLA-DR + CD8 + T cells, the proliferation of T cells, and circulating LPS levels were significantly reduced. The most recent study included a total of $20 \mathrm{HIV}$-1-infected subjects, who suffered from inadequate reconstitution of CD4+ T cells despite suppressive antiretroviral therapy [92]. These immunological nonresponders received chloroquine for six months in addition to HAART, which was well tolerated except for a skin rash in one case. Several immunological parameters improved as circulating LPS levels and activation of $\mathrm{CD} 4+\mathrm{T}$ cells and monocytes, and the production of inflammatory cytokines (IL-6, TNF-alpha) was reduced, documenting the immunomodulatory effect of adjuvant chloroquine treatment. Of note, the percentage (however not the absolute count) of circulating CD4+ T cells and PDC increas- ed, suggesting that sustained reduction of immune activation translates into clinical response. These preliminary data, however, should be interpreted with caution and need to be reproduced in larger cohorts of HIV-1-infected individuals. Such studies are in progress (ACTG A5258, http://clinicaltrials.gov/ct2/show/NCT00819390; CTN 246, http://www. clinical-studies/canadian-hivtrials-database/ctn-246/).

\section{Immune Modulation In Vivo}

The endosome is an interesting target for immune modulation, because drugs acting at this compartment are not associated with broad immunosuppression, which is well known for high-dose corticoid treatment. In this respect, it is interesting that chloroquine was enriched in adenoid tissues, thus being targeted to the center of the HIV-1-induced immunopathogenesis [93]. It should be considered that chloroquine may aggravate the peripheral unresponsiveness of PDC to TLR stimulation, as the IFN-alpha induction by CpG oligodeoxynucleotides and synthetic TLR7 agonists can also be blocked by chloroquine. These findings may explain why chloroquine administration in otherwise untreated HIV-1-infected patients has not prevailed in the past 15 years. Thus, chloroquine appears to be promising only if used in combination with suppressive antiretroviral therapy. Long-term studies will show whether chloroquine will help to restore PDC counts and function in the periphery, which will hopefully also reduce the frequency of non-AIDS-associated tumors. It also needs to be investigated whether 
chloroquine suffices to revert all signs of chronic immune activation. It may well be possible that a few HIV-1-infected patients will profit from a more potent reduction of immune activation. Potential candidates are biologicals used for the treatment of autoimmune diseases, for example, IL-6 receptor antagonists, antibodies against TNF-alpha, or soluble TNF-alpha receptors.

\section{Concluding Remarks}

The concept of chronic immune activation in the immunopathogenesis of HIV-1 infection has opened the door for adjuvant immunomodulatory therapies. Future will tell whether the antiretroviral therapy and quality of life of HIV-1-infected individuals can further be improved. Continuous efforts of basic and applied sciences and pharmaceutical companies are required to stay on an upward track.

\section{Conflict of Interests}

The authors declare no conflict of interests.

\section{Acknowledgments}

The authors thank Bernhard Fleckenstein for continuous support and Jay A. Levy for great mentorship. They acknowledge funding by the German Research Foundation (SCHM1702/2-2, SCHM1702/3-1), the graduate college 1071 ("Viruses of the immune system"), the IZKF (TP50), and the "Akademie der Wissenschaften und Literatur $\mathrm{zu}$ Mainz". They apologize to all appreciated colleagues whose data they may have overlooked.

\section{References}

[1] E. De Clercq, "Antiretroviral drugs," Current Opinion in Pharmacology, vol. 10, no. 5, pp. 507-515, 2010.

[2] T. Hawkins, "Understanding and managing the adverse effects of antiretroviral therapy," Antiviral Research, vol. 85, no. 1, pp. 201-209, 2010.

[3] S. G. Deeks, "HIV infection, inflammation, immunosenescence, and aging," Annual Review of Medicine, vol. 62, pp. 141155, 2011.

[4] J. Palefsky, "Human papillomavirus and anal neoplasia," Current HIV/AIDS Reports, vol. 5, no. 2, pp. 87-85, 2008.

[5] P. Fitzgerald-Bocarsly and E. S. Jacobs, "Plasmacytoid dendritic cells in HIV infection: striking a delicate balance," Journal of Leukocyte Biology, vol. 87, no. 4, pp. 609-620, 2010.

[6] J. P. Herbeuval and G. M. Shearer, "HIV-1 immunopathogenesis: how good interferon turns bad," Clinical Immunology, vol. 123, no. 2, pp. 121-128, 2007.

[7] F. Kirchhoff, "Is the high virulence of HIV-1 an unfortunate coincidence of primate lentiviral evolution?" Nature Reviews Microbiology, vol. 7, no. 6, pp. 467-476, 2009.

[8] M. Popovic, K. Tenner-Racz, C. Pelser et al., "Persistence of HIV-1 structural proteins and glycoproteins in lymph nodes of patients under highly active antiretroviral therapy," Proceedings of the National Academy of Sciences of the United States of America, vol. 102, no. 41, pp. 14807-14812, 2005.
[9] J. V. Giorgi, L. E. Hultin, J. A. McKeating et al., "Shorter survival in advanced human immunodeficiency virus type 1 infection is more closely associated with T lymphocyte activation than with plasma virus burden or virus chemokine coreceptor usage," Journal of Infectious Diseases, vol. 179, no. 4, pp. 859-870, 1999.

[10] M. D. Hazenberg, J. W. T. Stuart, S. A. Otto et al., “T-cell division in human immunodeficiency virus (HIV)-1 infection is mainly due to immune activation: a longitudinal analysis in patients before and during highly active antiretroviral therapy (HAART)," Blood, vol. 95, no. 1, pp. 249-255, 2000.

[11] Z. Liu, W. G. Cumberland, L. E. Hultin, H. E. Prince, R. Detels, and J. V. Giorgi, "Elevated CD38 antigen expression on $\mathrm{CD}^{+} \mathrm{T}$ cells Is a stronger marker for the risk of chronic HIV disease progression to AIDS and death in the multicenter AIDS Cohort study than $\mathrm{CD}^{+}$cell count, soluble immune activation markers, or combinations of HLA-DR and CD38 expression," Journal of Acquired Immune Deficiency Syndromes and Human Retrovirology, vol. 16, no. 2, pp. 83-92, 1997.

[12] A. E. Sousa, J. Carneiro, M. Meier-Schellersheim, Z. Grossman, and R. M. M. Victorino, "CD4 T cell depletion is linked directly to immune activation in the pathogenesis of HIV-1 and HIV-2 but only indirectly to the viral load," Journal of Immunology, vol. 169, no. 6, pp. 3400-3406, 2002.

[13] H. Valdez and M. M. Lederman, "Cytokines and cytokine therapies in HIV infection," AIDS Clinical Review, pp. 187228, 1997.

[14] I. Pandrea, D. L. Sodora, G. Silvestri, and C. Apetrei, "Into the wild: simian immunodeficiency virus (SIV) infection in natural hosts," Trends in Immunology, vol. 29, no. 9, pp. 419428, 2008.

[15] G. Silvestri, M. Paiardini, I. Pandrea, M. M. Lederman, and D. L. Sodora, "Understanding the benign nature of SIV infection in natural hosts," Journal of Clinical Investigation, vol. 117, no. 11, pp. 3148-3154, 2007.

[16] C. Kneitz, T. Kerkau, J. Muller et al., "Early phenotypic and functional alterations in lymphocytes from simian immunodeficiency virus infected macaques," Veterinary Immunology and Immunopathology, vol. 36, no. 3, pp. 239-255, 1993.

[17] J. M. Brenchley, T. W. Schacker, L. E. Ruff et al., "CD4+ T cell depletion during all stages of HIV disease occurs predominantly in the gastrointestinal tract," Journal of Experimental Medicine, vol. 200, no. 6, pp. 749-759, 2004.

[18] M. Guadalupe, E. Reay, S. Sankaran et al., "Severe CD4+ Tcell depletion in gut lymphoid tissue during primary human immunodeficiency virus type 1 infection and substantial delay in restoration following highly active antiretroviral therapy," Journal of Virology, vol. 77, no. 21, pp. 11708-11717, 2003.

[19] J. J. Mattapallil, D. C. Douek, B. Hill, Y. Nishimura, M. Martin, and M. Roederer, "Massive infection and loss of memory CD4+ T cells in multiple tissues during acute SIV infection," Nature, vol. 434, no. 7037, pp. 1093-1097, 2005.

[20] S. Mehandru, M. A. Poles, K. Tenner-Racz et al., "Primary HIV-1 infection is associated with preferential depletion of CD4+ T lymphocytes from effector sites in the gastrointestinal tract," Journal of Experimental Medicine, vol. 200, no. 6, pp. 761-770, 2004.

[21] L. J. Picker, S. I. Hagen, R. Lum et al., "Insufficient production and tissue delivery of CD4+ memory $\mathrm{T}$ cells in rapidly progressive simian immunodeficiency virus infection," Journal of Experimental Medicine, vol. 200, no. 10, pp. 1299-1314, 2004.

[22] R. S. Veazey, M. DeMaria, L. V. Chalifoux et al., "Gastrointestinal tract as a major site of CD4+ T cell depletion and viral 
replication in SIV infection," Science, vol. 280, no. 5362, pp. 427-431, 1998.

[23] J. M. Brenchley, D. A. Price, T. W. Schacker et al., "Microbial translocation is a cause of systemic immune activation in chronic HIV infection," Nature Medicine, vol. 12, no. 12, pp. 1365-1371, 2006.

[24] C. Leinert, C. Stahl-Hennig, A. Ecker et al., "Microbial translocation in simian immunodeficiency virus (SIV)-infected rhesus monkeys (Macaca mulatta)," Journal of Medical Primatology, vol. 39, no. 4, pp. 243-251, 2010.

[25] A. Isaacs and J. Lindenmann, "Virus interference. I. The interferon. By A. Isaacs and J. Lindenmann, 1957," Journal of Interferon Research, vol. 7, no. 5, pp. 429-438, 1987.

[26] S. Pestka, C. D. Krause, and M. R. Walter, "Interferons, interferon-like cytokines, and their receptors," Immunological Reviews, vol. 202, pp. 8-32, 2004.

[27] M. Cella, D. Jarrossay, F. Faccheth et al., "Plasmacytoid monocytes migrate to inflamed lymph nodes and produce large amounts of type I interferon," Nature Medicine, vol. 5, no. 8, pp. 919-923, 1999.

[28] F. P. Siegal, N. Kadowaki, M. Shodell et al., "The nature of the principal Type 1 interferon-producing cells in human blood," Science, vol. 284, no. 5421, pp. 1835-1837, 1999.

[29] P. Fitzgerald-Bocarsly and D. Feng, "The role of type I interferon production by dendritic cells in host defense," Biochimie, vol. 89, no. 6-7, pp. 843-855, 2007.

[30] N. Kadowaki, S. Ho, S. Antonenko et al., "Subsets of human dendritic cell precursors express different toll-like receptors and respond to different microbial antigens," Journal of Experimental Medicine, vol. 194, no. 6, pp. 863-869, 2001.

[31] M. Cella, F. Facchetti, A. Lanzavecchia, and M. Colonna, "Plasmacytoid dendritic cells activated by influenza virus and CD40L drive a potent TH1 polarization," Nature Immunology, vol. 1, no. 4, pp. 305-310, 2000.

[32] N. Kadowaki, S. Antonenko, J. Y. N. Lau, and Y. J. Liu, "Natural interferon $\alpha / \beta$-producing cells link innate and adaptive immunity," Journal of Experimental Medicine, vol. 192, no. 2, pp. 219-225, 2000.

[33] A. S. Beignon, K. McKenna, M. Skoberne et al., "Endocytosis of HIV-1 activates plasmacytoid dendritic cells via Toll-like receptor-viral RNA interactions," Journal of Clinical Investigation, vol. 115, no. 11, pp. 3265-3275, 2005.

[34] L. Fong, M. Mengozzi, N. W. Abbey, B. G. Herndier, and E. G. Engleman, "Productive infection of plasmacytoid dendritic cells with human immunodeficiency virus type 1 is triggered by CD40 ligation," Journal of Virology, vol. 76, no. 21, pp. 11033-11041, 2002.

[35] J. F. Fonteneau, M. Larsson, A. S. Beignon et al., "Human immunodeficiency virus type 1 activates plasmacytoid dendritic cells and concomitantly induces the bystander maturation of myeloid dendritic cells," Journal of Virology, vol. 78, no. 10, pp. 5223-5232, 2004.

[36] J. P. Herbeuval, A. W. Hardy, A. Boasso et al., "Regulation of TNF-related apoptosis-inducing ligand on primary CD4 + T cells by HIV-1: role of type I IFN-producing plasmacytoid dendritic cells," Proceedings of the National Academy of Sciences of the United States of America, vol. 102, no. 39, pp. 1397413979, 2005.

[37] J. P. Herbeuval, J. C. Grivel, A. Boasso et al., "CD4+ T-cell death induced by infectious and noninfectious HIV-1: role of type 1 interferon-dependent, TRAIL/DR5-mediated apoptosis," Blood, vol. 106, no. 10, pp. 3524-3531, 2005.
[38] A. Yonezawa, R. Morita, A. Takaori-Kondo et al., "Natural alpha interferon-producing cells respond to human immunodeficiency virus type 1 with alpha interferon production and maturation into dendritic cells," Journal of Virology, vol. 77, no. 6, pp. 3777-3784, 2003.

[39] A. Lepelley, S. Louis, M. Sourisseau et al., "Innate sensing of HIV-infected cells," PLoS Pathogens, vol. 7, no. 2, article e1001284, 2011.

[40] B. Schmidt, B. M. Ashlock, H. Foster, S. H. Fujimura, and J. A. Levy, "HIV-infected cells are major inducers of plasmacytoid dendritic cell interferon production, maturation, and migration," Virology, vol. 343, no. 2, pp. 256-266, 2005.

[41] S. Haupt, N. Donhauser, C. Chaipan et al., "CD4 binding affinity determines human immunodeficiency virus type 1-induced alpha interferon production in plasmacytoid dendritic cells," Journal of Virology, vol. 82, no. 17, pp. 8900-8905, 2008.

[42] E. Martinelli, C. Cicala, D. Van Ryk et al., "HIV-1 gp120 inhibits TLR9-mediated activation and IFN- $\alpha$ secretion in plasmacytoid dendritic cells," Proceedings of the National Academy of Sciences of the United States of America, vol. 104, no. 9, pp. 3396-3401, 2007.

[43] M. C. Milone and P. Fitzgerald-Bocarsly, "The mannose receptor mediates induction of IFN- $\alpha$ in peripheral blood dendritic cells by enveloped RNA and DNA viruses," Journal of Immunology, vol. 161, no. 5, pp. 2391-2399, 1998.

[44] B. Schmidt, I. Scott, R. G. Whitmore et al., "Low-level HIV infection of plasmacytoid dendritic cells: onset of cytopathic effects and cell death after PDC maturation," Virology, vol. 329, no. 2, pp. 280-288, 2004.

[45] P. U. Cameron, A. J. Handley, D. C. Baylis et al., "Preferential infection of dendritic cells during human immunodeficiency virus type 1 infection of blood leukocytes," Journal of Virology, vol. 81, no. 5, pp. 2297-2306, 2007.

[46] V. A. Evans, L. Lal, R. Akkina et al., "Thymic plasmacytoid dendritic cells are susceptible to productive HIV-1 infection and efficiently transfer R5 HIV-1 to thymocytes in vitro," Retrovirology, vol. 8, article 43, 2011.

[47] A. Smed-Sörensen, K. Loré, J. Vasudevan et al., "Differential susceptibility to human immunodeficiency virus type 1 infection of myeloid and plasmacytoid dendritic cells," Journal of Virology, vol. 79, no. 14, pp. 8861-8869, 2005.

[48] A. W. Hardy, D. R. Graham, G. M. Shearer, and J. P. Herbeuval, "HIV turns plasmacytoid dendritic cells (pDC) into TRAILexpressing killer pDC and down-regulates HIV coreceptors by Toll-like receptor 7-induced IFN- $\alpha$," Proceedings of the National Academy of Sciences of the United States of America, vol. 104, no. 44, pp. 17453-17458, 2007.

[49] M. O’Brien, O. Manches, R. L. Sabado et al., "Spatiotemporal trafficking of HIV in human plasmacytoid dendritic cells defines a persistently IFN- $\alpha$-producing and partially matured phenotype," Journal of Clinical Investigation, vol. 121, no. 3, pp. 1088-1101, 2011.

[50] F. Heil, H. Hemmi, H. Hochrein et al., "Species-Specific Recognition of Single-Stranded RNA via Till-like Receptor 7 and 8," Science, vol. 303, no. 5663, pp. 1526-1529, 2004.

[51] J. N. Mandl, A. P. Barry, T. H. Vanderford et al., "Divergent TLR7 and TLR9 signaling and type I interferon production dis-tinguish pathogenic and nonpathogenic AIDS virus infections," Nature Medicine, vol. 14, no. 10, pp. 1077-1087, 2008.

[52] P. M. Pitha, "Multiple effects of interferon on the replication of human immunodeficiency virus type 1," Antiviral Research, vol. 24, no. 2-3, pp. 205-219, 1994. 
[53] J. K. Yamamoto, F. Barre-Sinoussi, V. Bolton, N. C. Pedersen, and M. B. Gardner, "Human alpha- and beta-interferon but not gamma- suppress the in vitro replication of LAV, HTLVIII, and ARV-2," Journal of Interferon Research, vol. 6, no. 2, pp. 143-152, 1986.

[54] M. Altfeld, L. Fadda, D. Frleta, and N. Bhardwaj, "DCs and NK cells: critical effectors in the immune response to HIV-1," Nature Reviews Immunology, vol. 11, no. 3, pp. 176-186, 2011.

[55] J. P. Herbeuval, J. Nilsson, A. Boasso et al., "Differential expression of IFN- $\alpha$ and TRAIL/DR5 in lymphoid tissue of progressor versus nonprogressor HIV-1-infected patients," Proceedings of the National Academy of Sciences of the United States of America, vol. 103, no. 18, pp. 7000-7005, 2006.

[56] A. Boasso, J. P. Herbeuval, A. W. Hardy et al., "HIV inhibits CD4+ T-cell proliferation by inducing indoleamine 2,3-dioxygenase in plasmacytoid dendritic cells," Blood, vol. 109, no. 8, pp. 3351-3359, 2007.

[57] A. Boasso, A. W. Hardy, S. A. Anderson, M. J. Dolan, and G. M. Shearer, "HIV-induced type I interferon and tryptophan catabolism drive $\mathrm{T}$ cell dysfunction despite phenotypic activation," PLoS ONE, vol. 3, no. 8, Article ID e2961, 2008.

[58] O. Manches, D. Munn, A. Fallahi et al., "HIV-activated human plasmacytoid DCs induce Tregs through an indoleamine 2,3dioxygenase-dependent mechanism," Journal of Clinical Investigation, vol. 118, no. 10, pp. 3431-3439, 2008.

[59] J. H. Meyers, J. S. Justement, C. W. Hallahan et al., "Impact of HIV on cell survival and antiviral activity of plasmacytoid dendritic cells," PLoS ONE, vol. 2, no. 5, article e458, 2007.

[60] J. C. Tilton, M. M. Manion, M. R. Luskin et al., "Human immunodeficiency virus viremia induces plasmacytoid dendritic cell activation in vivo and diminished alpha interferon production in vitro," Journal of Virology, vol. 82, no. 8, pp. 39974006, 2008.

[61] M. Meythaler, A. Martinot, Z. Wang et al., "Differential CD4+ T-lymphocyte apoptosis and bystander T-cell activation in rhesus macaques and sooty mangabeys during acute simian immunodeficiency virus infection," Journal of Virology, vol. 83, no. 2, pp. 572-583, 2009.

[62] S. E. Bosinger, Q. Li, S. N. Gordon et al., "Global genomic analysis reveals rapid control of a robust innate response in SIVinfected sooty mangabeys," Journal of Clinical Investigation, vol. 119, no. 12, pp. 3556-3572, 2009.

[63] O. M. Diop, M. J. Y. Ploquin, L. Mortara et al., "Plasmacytoid dendritic cell dynamics and alpha interferon production during simian immunodeficiency virus infection with a nonpathogenic outcome," Journal of Virology, vol. 82, no. 11, pp. 51455152, 2008.

[64] L. D. Harris, B. Tabb, D. L. Sodora et al., "Downregulation of robust acute type I interferon responses distinguishes nonpathogenic simian immunodeficiency virus (SIV) infection of natural hosts from pathogenic SIV infection of rhesus macaques," Journal of Virology, vol. 84, no. 15, pp. 7886-7891, 2010.

[65] B. Jacquelin, V. Mayau, B. Targat et al., "Nonpathogenic SIV infection of African green monkeys induces a strong but rapidly controlled type I IFN response," Journal of Clinical Investigation, vol. 119, no. 12, pp. 3544-3555, 2009.

[66] J. Abb, R. Zachoval, V. Zachoval, and F. Deinhardt, "HIV antigen, HIV antibody and serum interferon in a patient with encephalopathy," Infection, vol. 15, no. 6, pp. 425-426, 1987.

[67] T. Minagawa, K. Mizuno, S. Hirano et al., "AIDS research communications: detection of high levels of immunoreactive human beta-1 interferon in sera from HIV-infected patients," Life Sciences, vol. 45, no. 11, pp. iii-vii, 1989.
[68] M. von Sydow, A. Sonnerborg, H. Gaines, and O. Strannegard, "Interferon-alpha and tumor necrosis factor-alpha in serum of patients in various stages of HIV-1 infection," AIDS Research and Human Retroviruses, vol. 7, no. 4, pp. 375-380, 1991.

[69] J. Chehimi, E. Papasavvas, C. Tomescu et al., "Inability of plasmacytoid dendritic cells to directly lyse HIV-infected autologous CD4+ T cells despite induction of tumor necrosis factor-related apoptosis-inducing ligand," Journal of Virology, vol. 84, no. 6, pp. 2762-2773, 2010.

[70] N. M. Sherer, M. J. Lehmann, L. F. Jimenez-Soto, C. Horensavitz, M. Pypaert, and W. Mothes, "Retroviruses can establish filopodial bridges for efficient cell-to-cell transmission," $\mathrm{Na}$ ture Cell Biology, vol. 9, no. 3, pp. 310-315, 2007.

[71] Q. Sattentau, "Avoiding the void: cell-to-cell spread of human viruses," Nature Reviews Microbiology, vol. 6, no. 11, pp. 815826, 2008.

[72] M. Nascimbeni, L. Perié, L. Chorro et al., "Plasmacytoid dendritic cells accumulate in spleens from chronically HIV-infected patients but barely participate in interferon- $\alpha$ expression," Blood, vol. 113, no. 24, pp. 6112-6119, 2009.

[73] S. Kwa, S. Kannanganat, P. Nigam et al., "Plasmacytoid dendritic cells are recruited to the colorectum and contribute to immune activation during pathogenic SIV infection in rhesus macaques," Blood, vol. 118, no. 10, pp. 2763-2773, 2011.

[74] J. Chehimi, D. E. Campbell, L. Azzoni et al., "Persistent decreases in blood plasmacytoid dendritic cell number and function despite effective highly active antiretroviral therapy and increased blood myeloid dendritic cells in HIV-infected individuals," Journal of Immunology, vol. 168, no. 9, pp. 47964801, 2002.

[75] N. Donhauser, M. Helm, K. Pritschet et al., "Differential effects of P-class versus other CPG oligodeoxynucleotide classes on the impaired innate immunity of plasmacytoid dendritic cells in HIV type 1 infection," AIDS Research and Human Retroviruses, vol. 26, no. 2, pp. 161-171, 2010.

[76] S. Feldman, D. Stein, S. Amrute et al., "Decreased interferon- $\alpha$ production in HIV-infected patients correlates with numerical and functional deficiencies in circulating type 2 dendritic cell precursors," Clinical Immunology, vol. 101, no. 2, pp. 201-210, 2001.

[77] J. S. Finke, M. Shodell, K. Shah, F. P. Siegal, and R. M. Steinman, "Dendritic cell numbers in the blood of HIV-1 infected patients before and after changes in antiretroviral therapy," Journal of Clinical Immunology, vol. 24, no. 6, pp. 647-652, 2004.

[78] F. P. Siegal, P. Fitzgerald-Bocarsly, B. K. Holland, and M. Shodell, "Interferon- $\alpha$ generation and immune reconstitution during antiretroviral therapy for human immunodeficiency virus infection," AIDS, vol. 15, no. 13, pp. 1603-1612, 2001.

[79] R. L. Sabado, M. O’Brien, A. Subedi et al., "Evidence of dysregulation of dendritic cells in primary HIV infection," Blood, vol. 116, no. 19, pp. 3839-3852, 2010.

[80] J. A. Martinson, A. R. Tenorio, C. J. Montoya et al., "Impact of class A, B and C CpG-oligodeoxynucleotides on in vitro activation of innate immune cells in human immunodeficiency virus-1 infected individuals," Immunology, vol. 120, no. 4, pp. 526-535, 2007.

[81] B. Schmidt, S. H. Fujimura, J. N. Martin, and J. A. Levy, "Variations in plasmacytoid dendritic cell (PDC) and myeloid dendritic cell (MDC) levels in HIV-infected subjects on and off antiretroviral therapy," Journal of Clinical Immunology, vol. 26, no. 1, pp. 55-64, 2006. 
[82] I. Ratnam, C. Chiu, N. B. Kandala, and P. J. Easterbrook, "Incidence and risk factors for immune reconstitution inflammatory syndrome in an ethnically diverse HIV type 1-infected cohort," Clinical Infectious Diseases, vol. 42, no. 3, pp. 418-427, 2006.

[83] J. Lund, A. Sato, S. Akira, R. Medzhitov, and A. Iwasaki, “Tolllike receptor 9-mediated recognition of Herpes simplex virus2 by plasmacytoid dendritic cells," Journal of Experimental Medicine, vol. 198, no. 3, pp. 513-520, 2003.

[84] P. A. Fox, M. Nathan, N. Francis et al., "A double-blind, randomized controlled trial of the use of imiquimod cream for the treatment of anal canal high-grade anal intraepithelial neoplasia in HIV-positive MSM on HAART, with long-term follow-up data including the use of open-label imiquimod," AIDS, vol. 24, no. 15, pp. 2331-2335, 2010.

[85] A. Ulmer, M. Müller, B. Bertisch-Möllenhoff, and B. Frietsch, "Low dose prednisolone reduces CD4+ T cell loss in therapynaive HIV-patients without antiretroviral therapy," European Journal of Medical Research, vol. 10, no. 3, pp. 105-109, 2005.

[86] A. Ulmer, M. Müller, B. Bertisch-Möllenhoff, and B. Frietsch, "Low-dose prednisolone has a CD4-stabilizing effect in pretreated HIV-patients during structured therapy interruptions (STI)," European Journal of Medical Research, vol. 10, no. 6, pp. 227-232, 2005.

[87] A. Gringeri, E. Santagostino, M. Cusini et al., "Absence of clinical, virological, and immunological signs of progression in HIV-1-infected patients receiving active anti-interferon- $\alpha$ immunization: a 30-month follow-up report," Journal of Acquired Immune Deficiency Syndromes and Human Retrovirology, vol. 13, no. 1, pp. 55-67, 1996.

[88] A. Gringeri, M. Musicco, P. Hermans et al., "Active anti-interferon- $\alpha$ immunization: a European-Israeli, randomized, double-blind, placebo-controlled clinical trial in 242 HIV-1-infected patients (the EURIS study)," Journal of Acquired Immune Deficiency Syndromes and Human Retrovirology, vol. 20, no. 4, pp. 358-370, 1999.

[89] J. A. Martinson, C. J. Montoya, X. Usuga, R. Ronquillo, A. L. Landay, and S. N. Desai, "Chloroquine modulates HIV-1-induced plasmacytoid dendritic cell alpha interferon: implication for T-cell activation," Antimicrobial Agents and Chemotherapy, vol. 54, no. 2, pp. 871-881, 2010.

[90] Z. Hong, Z. Jiang, W. Liangxi et al., "Chloroquine protects mice from challenge with CpG ODN and LPS by decreasing proinflammatory cytokine release," International Immunopharmacology, vol. 4, no. 2, pp. 223-234, 2004.

[91] S. M. Murray, C. M. Down, D. R. Boulware et al., "Reduction of immune activation with chloroquine therapy during chronic HIV infection," Journal of Virology, vol. 84, no. 22, pp. 12082-12086, 2010.

[92] S. Piconi, S. Parisotto, G. Rizzardini et al., "Hydroxychloroquine drastically reduces immune activation in HIV-infected, antiretroviral therapy-treated immunologic nonresponders," Blood, vol. 118, no. 12, pp. 3263-3272, 2011.

[93] L. Aguirre-Cruz, K. J. Torres, H. Jung-Cook et al., "Short communication: preferential concentration of hydroxychloroquine in adenoid tissue of HIV-infected subjects," AIDS Research and Human Retroviruses, vol. 26, no. 3, pp. 339-342, 2010. 


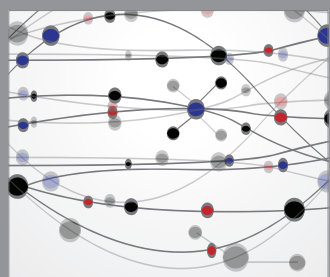

The Scientific World Journal
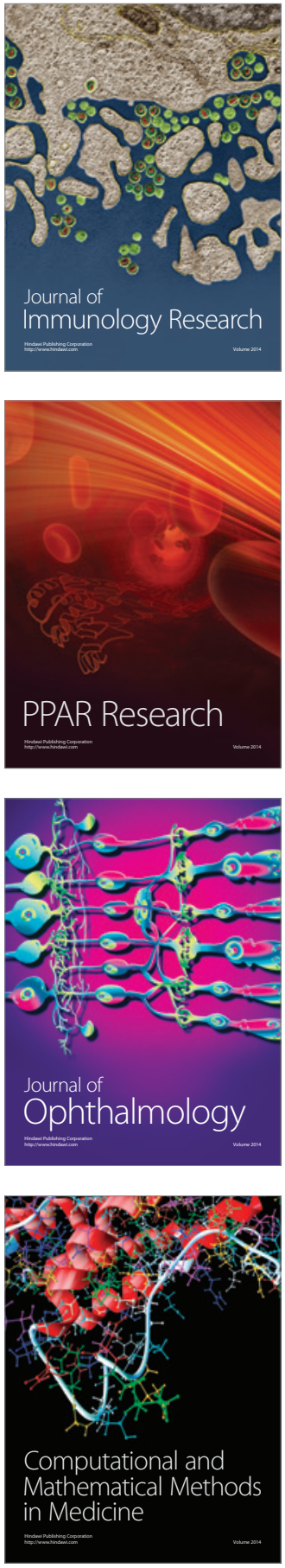

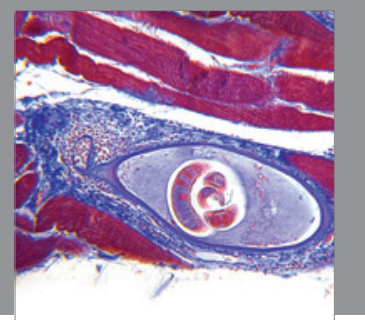

Gastroenterology

Research and Practice
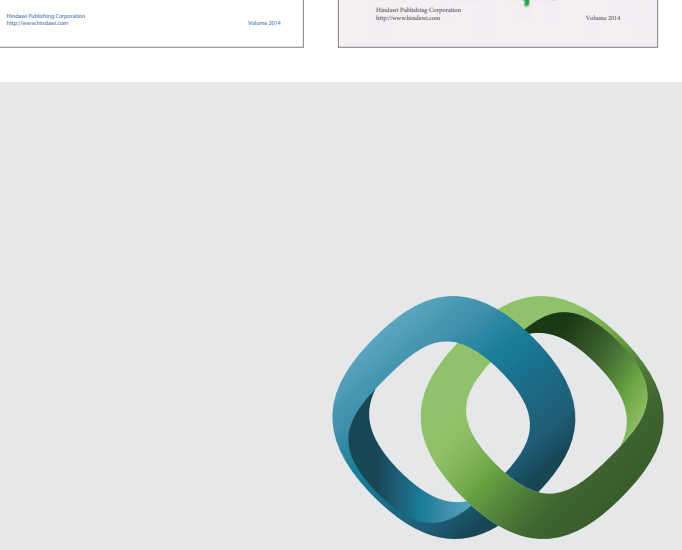

\section{Hindawi}

Submit your manuscripts at

http://www.hindawi.com
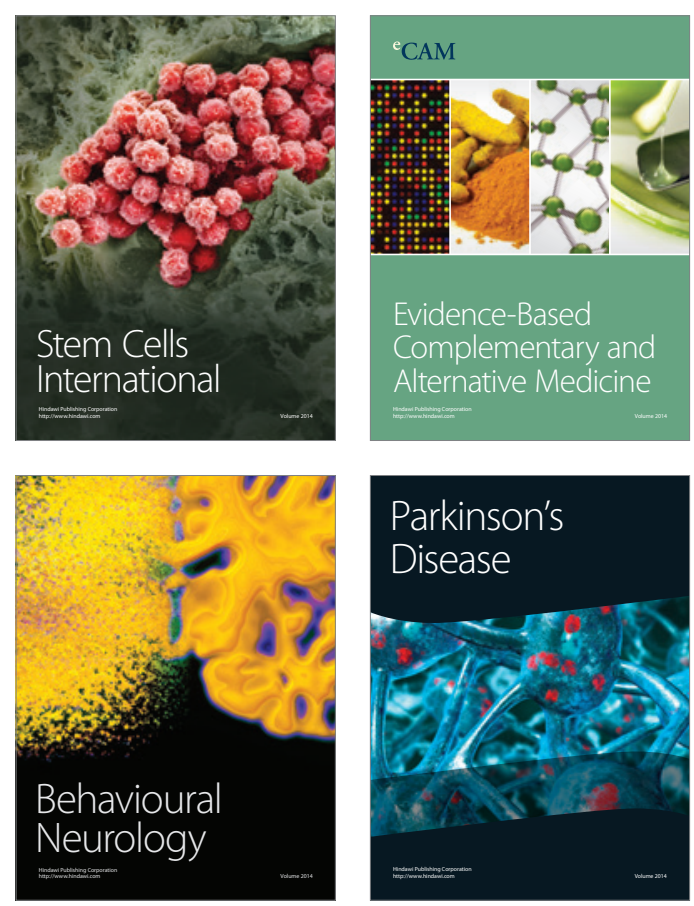

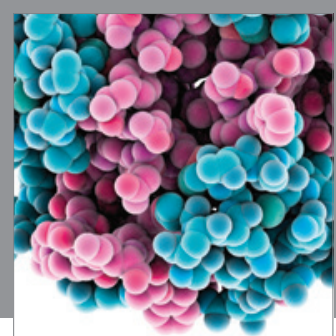

Journal of
Diabetes Research

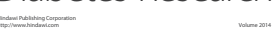

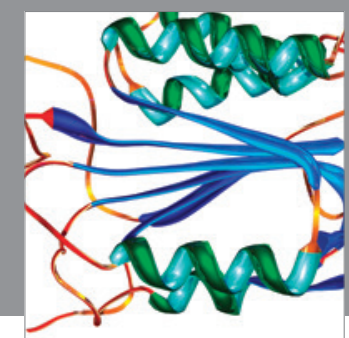

Disease Markers
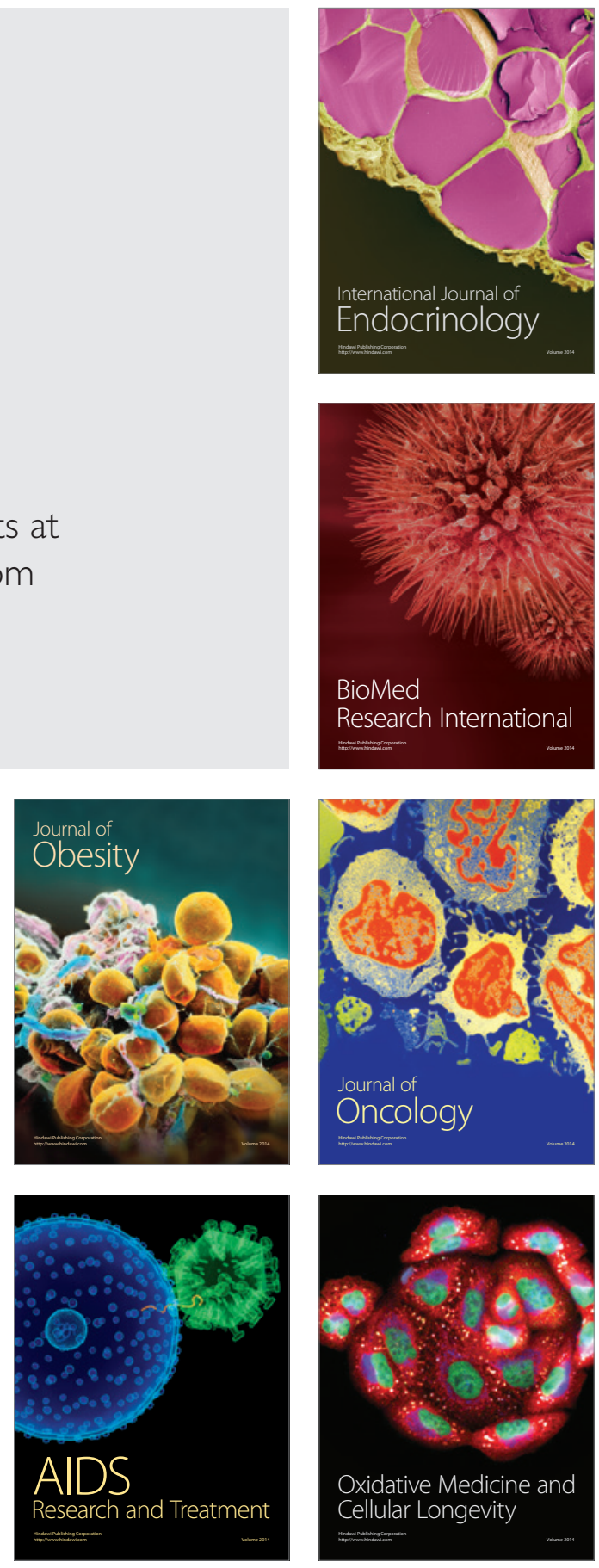